\title{
Assessment of different types of materials of children treated under general anesthesia
}

\author{
Radosveta Andreeva \\ Department of pediatric dentistry, Faculty of Dental \\ Medicine, Medical University of Varna;
}

\begin{abstract}
Pharmacological behavior management is necessary for young children with extensive caries (ECC), children with special health care needs and non-cooperative children.

The aim of this study is to assess the different types of materials used for the dental treatment of children under general anesthesia and the average number of extraction according to the age. The retrospective study covered the medical documentation of 395 children (4909 teeth) treated under general anesthesia. The patients are divided in 3 groups according to the age: 0-5 years (3106 teeth); 5-12 years (1568 teeth); 12-18 years (235 teeth). The assessment of extractions and the materials, used for the treatment of children, was done by calculation of the average number of extracted teeth and the teeth, treated by different materials.

Results: The usage of glass - jonomer cement (GJC) are more commonly used filling material in the smallest age group (1-5) years with an average value of 8,035 $\pm 2,03$ filled teeth per child. There is a statistically significant difference in usage of GJC between the different age groups $(p=0.0001)$. The average number of stainless and zircon crowns are significantly more used in the first age group with an average values of 1,25 $\pm 1,065$ per child. Composite restorations are mostly used in the third age group - 4,53 $\pm 0,046$ filled teeth per child. The average number of extractions for all age groups is 3,56 $\pm 1,52$.
\end{abstract}


Conclusion: In the different age groups of children treated under general anesthesia, different materials are preferred. The restorations are more than the extracted teeth.

Keywords: general anesthesia, type of materials, teeth extractions.

\section{Introduction}

Complete planning aims at ensuring that all the treatment required is carried out under a single GA. The practice of extracting the teeth with periodontitis and leaving restorable teeth for future visits as an outpatient using local anesthesia with or without sedation is to be avoided. This has been shown to result in a high rate of repeat general anesthesia GA $(1,2)$. The inability of the child to accept treatment using local anesthesia is an important factor in determining the need for general anesthesia and the need of a protocol for treatment of children by narcosis. Restorative procedures and simple extractions are the most frequent types of treatment. Studies have shown that the quality of restorations carried out under GA is considerably better than under local anesthesia due to more effective moisture control and more accurate placement of planned restorations $(3,4)$. However, treatment under GA is a costly method of delivering dental care, and access to it is often limited due to long waiting periods in most hospitals as well as travel costs (5).

\section{Aim}

The aim: The aim of this study is to assess the different types of materials used for the dental treatment of children under general anesthesia and the average number of extraction according to the age.

\section{Materials and methods}

The retrospective study covered the medical documentation of 395 children ( $n=4909$ teeth) treated under general anesthesia. The patients are divided in 3 groups according to the age: $0-5$ years ( $n=3106$ teeth); 5-12 years ( $n=1568$ teeth); $12-18$ years ( $n=235$ teeth). The assessment of extractions and the materials, used for the treatment of children, was done by calculation of the number of extracted teeth and the teeth, treated by different materials. The number of primary and permanent teeth extracted and restored, and the type of restoration was recorded. Data were collected from records of patients who required full mouth rehabilitation under general anesthesia over a period of three years. 


\section{Results and discussion:}

Table 1: Average number of different types of materials and extractions according to the studied age groups of children treated under general anesthesia.

\begin{tabular}{|c|c|c|c|c|c|}
\hline \multirow[t]{2}{*}{ Dental materials and extractions } & \multicolumn{5}{|c|}{ Age group/n-number of treated teeth } \\
\hline & $\begin{array}{l}\text { 0-5years } \\
\text { (1) }\end{array}$ & $\begin{array}{l}5-12 \text { years } \\
(2)\end{array}$ & $\begin{array}{l}12 \text {-18years } \\
\text { (3) }\end{array}$ & Total & $\begin{array}{l}\text { T-test } \\
P \text {-value }\end{array}$ \\
\hline $\begin{array}{l}\text { GJC restorations - average teeth } \\
\text { number per child }( \pm S D)\end{array}$ & $\begin{array}{c}n=1591 \\
8,035 \pm 2,03\end{array}$ & $\begin{array}{c}n=477 \\
2,86 \pm 1,18\end{array}$ & $\begin{array}{c}n=2 \\
0,067 \pm 0,26\end{array}$ & $\begin{array}{c}n=2070 \\
3,65 \pm 1,16\end{array}$ & $\begin{array}{l}t_{1,2}=28.98 \\
P=0,00001 \\
t_{1,3}=21.11 \\
P=0,00001 \\
t_{2,3}=12.76 \\
P=0,00001\end{array}$ \\
\hline $\begin{array}{l}\text { Composite restorations - average } \\
\text { teeth number per child }( \pm S D)\end{array}$ & $\begin{array}{c}n=585 \\
2,95 \pm 0,99\end{array}$ & $\begin{array}{c}n=391 \\
2,34 \pm 0,95\end{array}$ & $\begin{array}{c}n=132 \\
4,53 \pm 0,046\end{array}$ & $\begin{array}{c}n=1108 \\
3,27 \pm 0,66\end{array}$ & $\begin{array}{c}t_{1,2}=5.85 \\
P=0,00001 \\
t_{1,3}=-8.25 \\
P=0,00001 \\
t_{2,3}=-11.21 \\
P=0,00001\end{array}$ \\
\hline $\begin{array}{l}\text { Fissure sealants - average teeth } \\
\text { number per child }( \pm S D)\end{array}$ & $\begin{array}{c}n=0 \\
0\end{array}$ & $\begin{array}{c}n=345 \\
2,07 \pm 1,23\end{array}$ & $\begin{array}{c}n=70 \\
2,33 \pm 1,32\end{array}$ & $\begin{array}{c}n=415 \\
1,47 \pm 0,85\end{array}$ & $\begin{array}{c}t_{1,2}=-23.77 \\
P=0,00001 \\
t_{1,3}=-26.01 \\
P=0,00001 \\
t_{2,3}=-1.34 ; \\
P=0,091\end{array}$ \\
\hline $\begin{array}{l}\text { Crowns(Stainless steel or zircon) - } \\
\text { average number per child ( } \pm S D \text { ) }\end{array}$ & $\begin{array}{c}\mathrm{n}=248 \\
1,25 \pm 1,065\end{array}$ & $\begin{array}{c}n=119 \\
0,71 \pm 0,60\end{array}$ & $\begin{array}{c}n=14 \\
0,47 \pm 0,51\end{array}$ & $\begin{array}{c}n=381 \\
0,81 \pm 0,73\end{array}$ & $\begin{array}{r}t_{1,2}=5.76 \\
P=0,00001 \\
t_{1,3}=3.82 \\
P=0,00009 \\
t_{2,3}=1.98 \\
P=0,02484\end{array}$ \\
\hline $\begin{array}{l}\text { Extractions - average number per } \\
\text { child }( \pm S D)\end{array}$ & $\begin{array}{c}n=930 \\
4,69 \pm 1,84\end{array}$ & $\begin{array}{c}n=660 \\
3,95 \pm 1,67\end{array}$ & $\begin{array}{c}n=61 \\
2,03 \pm 1,05\end{array}$ & $\begin{array}{c}n=1651 \\
3,56 \pm 1,52\end{array}$ & $\begin{array}{c}t_{1,2}=3.88 \\
P=0,00006 \\
t_{1,3}=7.40 \\
P=0,00001 \\
t_{2,3}=5.82 \\
P=0,00001\end{array}$ \\
\hline
\end{tabular}


The use of GJC is more common in the smallest age group (0-5 years). The average value of GJC fillings per child is ( $n=1591) 8,035 \pm 2,03$. Some authors report that GJC are the most used material in children with primary dentition both treated under general anesthesia or in the dental offices with routine methods $(1,7,8,9)$. The values for the second and the third age groups are as follow: $(n=477) 2,86 \pm 1,18$ and $(n=2) 0,067 \pm 0,26$. There is a statistically significant difference between the different age groups $(p=$ 0.0001). The stainless steel and zirconia crowns are more used in the first group (0-5 years), with an average value $(n=248) 1,25 \pm 1,065$. The values for the second and the third age groups are as follows: $(n=119) 0,71 \pm 0,60$ and $(n=14) 0,47 \pm 0,51$. There is a statistically significant difference between different age groups $(p=0.0001)$. Most of the teeth treated under general anesthesia are strongly destroyed. This necessitates the use of preformed crowns. That is why there is an increasing usage of preformed metal and zircon crowns in dental practice under general anesthesia. Our results are similar to the results of other authors $(1,2,6,9)$. The use of composite is more common in the third age group (12-18 years). The average value of composite fillings per child is $(n=132) 4,53 \pm 0,0468$. In the first studied group, the value is $(n=585) 2,95 \pm 0,99$ and in the second $(n=391) 2,34 \pm 0,95$. For the children aged between 0 and 5 years, with primary dentition, the composite fillings are not so useful as it is in children with mixed and permanent dentition. Composite materials are preferred outlaying materials for permanent teeth because they have better strength and aesthetics $(1,5,6)$.In the first examined group sealants were no used. The usage of

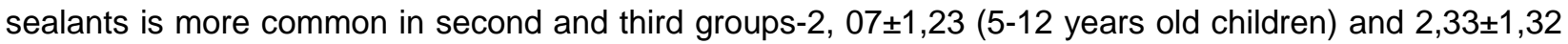
(12-18 years old children). The placement of sealants is a prophylactic measure that is most effective in the first three years after the tooth eruption of permanent teeth, when their mineralization is not complete. The newly erupted teeth are more retentive. At this age, most of the children have poor eating habits and neglected oral hygiene, their permanent molars more vulnerable to the aggressive oral environment. Therefore this preventive measure is mandatory. The prophylaxis of caries lesions by using sealant is recommended by soma other authors $(3,4,11)$. The average number of extractions for all age groups is $3,56 \pm 1,52$. The average values of tooth extractions for the different age groups are as fallow: for the age

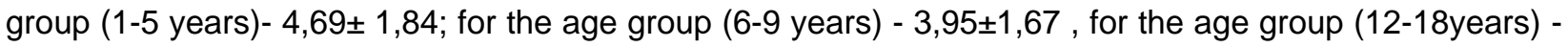
$2,03 \pm 1,05$. There is statistically significant difference between tooth extractions in the different age groups. The mean number of the restored teeth in the different age groups are significantly more than the mean number of the extracted teeth. Our results are similar to many others $(6,7,8)$. The reported extraction rate is higher in some articles compared to our published results. This is due to the more radical treatment approach when general anesthesia is used. This approach greatly reduces the need for re-treatment ( 9 , 10, 11). 


\section{Conclusion}

The complete oral rehabilitation of children treated under general anesthesia includes mainly teeth restorations and extractions. In the different age groups of children treated under general anesthesia, different type of materials are preferred. The average number of restorations is higher than extractions.

\section{References}

1. Harrison $\mathrm{M}$, Nutting L. Repeat general anaesthesia for paediatric dentistry. $\mathrm{Br}$ Dent $\mathrm{J}$ 2000;189(1):37-9.

2. Camilleri C, Roberts G, Ashley P, Scheer B. Analysis of paediatric dental care under general anaesthesi

3. Tate AR, Ng MW, Needleman HL, Acs G. Failure rates of restorative procedures following dental rehabilitation under general anesthesia. Pediatr Dent 2002;24:69-71.

4. Eidelman E, Faibis S, Peretz B. A comparison of restorations for children with early childhood caries treated undergeneral anesthesia or conscious sedation. Pediatr Dent2000;22:33-7.

5. Birute Jan causkiene,Jorma I.Virtanen et al,treatment under general anesthesia among children younger than 6 years in Lihuania.Medicina(Kaunas)2013;49(9):403-8

6. Savanheimo N, Sundberg SA, Virtanen JI, Vehkalahti MM. Dental care and treatments provided under general anaesthesia in the Helsinki Public Dental Service. BMC Oral Health 2012;12:45.

7. Vinckier F, Gizani S, Declerck D.Comprehensive denta care for children with rampant caries under general anaesthesia.Int J Paediatr Dent 2001;11:25-32.

8. Haubek D, Fuglsang M, Poulsen S, Rølling I. Dental treatment of children referred to general anaesthesia - association with country of origin and medical status. Int J Paediatr Dent 2006;16:239-46.

9. Moles DR, Ashley P: Hospital admissions for dental care in children: England 1997-2006. Br Dent J 2009;206:E214.

10. Karim ZA, Musa N, Noor SN. Utilization of dental general anaesthesia for children. Malays J Med Sci 2008;15:31-9.

11. Olak J, Saag M, Honkala S, Nõmmela R, Runnel R, Honkala E, et al. Children's dental fear in relation to dental health and parental dental fear. Stomatologija 2013;15:26-31.

\section{Corresponding author:}

Radosveta Andreeva

Department of pediatric dentistry, Faculty of Dental Medicine, Medical University of Varna email: doctor_ra@abv.bg 